\title{
IAWS President`s Message
}

\section{Yoon Soo Kim}

๑) Springer-Verlag GmbH Germany, part of Springer Nature 2020

It is my honor to be presented with an opportunity to follow in the footsteps of former Presidents of the Academy. The predecessors established the prestige of our Academy and contributed to widen the horizon of wood science for the past 50 years. First of all, I would like to thank immediate President Robert Evans. I would like to express my deep gratitude for his successful organization of plenary meetings over the past three years in Bali, Guadalajara and Moscow. He also contributed to increase the number of affiliate members and tackle the unbalance of gender and geography in the Fellows. I am grateful for Robert to remain on the EC as the former President and expect to play an important role in the next three years. I would also like to thank past President Uwe Schmitt, who now leaves the EC after serving as secretary, vice president and president for 18 years. We have benefited enormously from his knowledge and enthusiasm. We pay tribute to Robert and Uwe's commitment for the progress of the Academy.

The unprecedented outbreak of the pandemic COVID-19 is also affecting the business of the Academy. Recently, an EC meeting was held last June 18th via Zoom, much later than planned (later than the scheduled date in March). We welcomed Stavros Avramidis as newly elected vice president of the Academy. Some businesses are behind schedule due to the pandemic. Though belated, we have to elect board members to replace the four Fellows Roni Aloni, Aldo Ballerini, Todd Shupe and Keiji Takabe. I extend my thanks to those who have completed their term as board members. Robert is now chairing the nomination committee for recommendation of the candidates for board member with Roberta Farrell and Pieter Baas. The Academy Board under the chair of Siqun Wang successfully selected three PhD awardees. This year's plenary meeting to be held in concomitant with Biocom 2020 in Korea was canceled due to the pandemic. Instead, we are planning a half-day plenary meeting via teleconference at the end of this year.

The coronavirus pandemic has caused significant changes in our daily life. I am very much concerned about this pandemic and wonder when we can fully return to the "old normal." Even if the pandemic is under control, the anxiety will linger for a long time, and for the time being, large gatherings and travel are likely to remain tightly restricted. Under such a situation, the Academy has to prepare for a new journey. I seek to harness the Bulletin as a new source of communication. Lloyd as a bulletin editor and all EC 
members are trying to do their best to activate the bulletin as a platform of communication, not just for our Fellows but also for all those concerned. I hope that the bulletin will serve as a portal of exchanging information and ideas, sharing comments on the recent achievements in $R \& D$, activities in universities or institutes. Many institutes are going through radical restructuring. However, we are not aware of realities in those restructures. Education in wood science is also an interesting topic. Changes in curricula to keep a balance between the responsibility of education and the accountability of research is an interesting topic that draws our attention.

Last but not least, COVID-19 would be a stress test of our solidarity. Regardless of gender and biogeography, our Fellows so far have been showing the strong solidarities for the progress of knowledge in wood science. I sincerely hope that the Academy will continue to overcome the "self-centered" mindset and to rekindle the cooperative souls beyond the limits of the established value system. We need new lenses to see something that would remain invisible so far. To stay open to new encounters is our destiny as scientists, although it would be a painful task. I would like to remind fellows of Martin Buber saying "All real living is encountering." Virtues of clear-sightedness, stimulation and tolerance are our assets in the Academy. I look forward to meet you again anytime and anywhere. Until then, I wish all the Fellows good health and peace.

\section{Prof. Yoon Soo Kim \\ Gwangju, Korea}

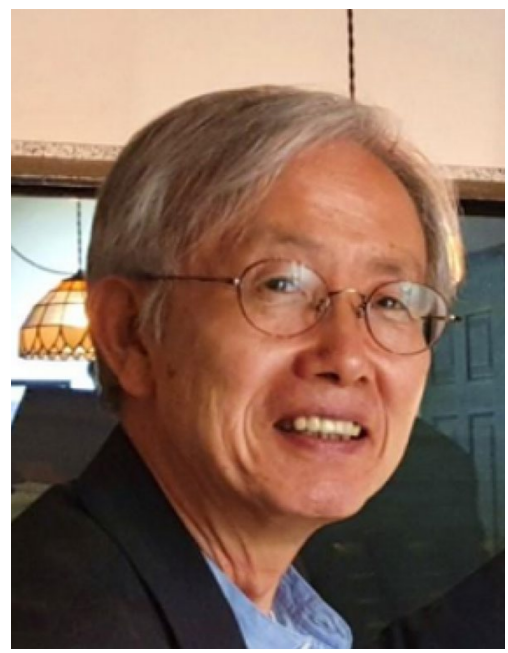

Publisher's Note Springer Nature remains neutral with regard to jurisdictional claims in published maps and institutional affiliations. 